Acta Theriologica 44 (2): 195-206, 1999.

PL ISSN 0001-7051

\title{
Winter bed-site selection by red deer Cervus elaphus xanthopygus and roe deer Capreolus capreolus bedfordi in forests of northeastern China
}

\author{
Huapeng CHEN, Feng LI, Liyang LUO, Huai WANG, \\ Jianzhang MA and Fei LI
}

\begin{abstract}
Chen H., Li F., Luo L., Wang H., Ma J. and Li F. 1999. Winter bed-site selection by red deer Cervus elaphus xanthopygus and roe deer Capreolus capreolus bedfordi in forests of northeastern China. Acta Theriologica 44: 195-206.

Winter bedding sites used by red deer Cervus elaphus xanthopygus Milne-Edwards, 1867 and roe deer Capreolus capreolus bedfordi Thomas, 1908 were studied in the forests of northeastern China from 1991 to 1992. Night beds used by both cervids were higher in canopy closure than day beds. Roe deer selected night bedding sites with denser canopy closure and higher percentage of coniferous trees, and day beds with better concealment cover than red deer. Roe deer selected night beds with higher canopy closure during cold mid winter period than during early and late winter period, whereas no such difference existed in day beds. Red deer showed no significant difference in canopy closure over day and night beds between mid and late winter. Canopy closure, composition of coniferous species, average distance to the nearest tree, and ground cover were identified to discriminate night and day beds for both cervids. The difference in selection of bed-site may reflect different energy requirements of large-bodied red deer and small-bodied roe deer.

College of Wildlife Resources, Northeast Forestry University, Harbin, P. R. China 150040; e-mail: chenhp@ihw.com.cn

Key words: Cervus elaphus xanthopygus, Capreolus capreolus bedfordi, bed-site, principal component analysis, discriminant functional analysis, China
\end{abstract}

\section{Introduction}

Red deer Cervus elaphus xanthopygus Milne-Edwards, 1867 and roe deer Capreolus capreolus bedfordi Thomas, 1908 are the most important cervids which overlap broadly in the forests of northeastern China. However, our understanding of their habitat selection in sympatry remains extremely limited. As yet, there were only three studies which separately reported the winter habitat selection by red deer and roe deer in northeastern China (Chang and Xiao 1988, Zhang and Xiao 1990, Jiang et al. 1996).

Availability and quality of forages used by red deer and roe deer dropped dramatically to the lowest point in forests of northeastern China during winter (Ma et al. 1996, Chen et al. 1998a). Energy was demonstrated to be a key limiting factor 
to survival of wintering red deer and roe deer (Chen and Xiao 1989, 1991, Chen et al. 1998a, b). Low temperatures, high wind speeds and deep snow cover may further increase energy demands for survival and the risk of hypothermia (Moen 1976, Parker and Robbins 1984). Thus, winter is considered to be a critical period for deer in temperate regions (Mautz 1978, Verme and Ullrey 1984).

Optimum habitat for deer has been described in terms of the amount and arrangement of cover and forage areas (Schmitz 1991, Mysterud and Østbye 1995). Cover potentially provides protection against adverse weather and predators (Skovlin 1982). During winter, temperate deer minimize their energy requirements both by reducing metabolic rates and body temperatures and by bedding in conifer shelter (Moen 1985, Risenhoover 1986, Smith et al. 1986, Mysterud and Østbye 1995). Bed-site selection seems to play an important role as part of an energy-conserving strategy and could affect deer survival during severe winters.

Red deer has larger body weight and a lower weight-specific metabolic rate than roe deer, and roe deer also probably have a higher critical temperature (LCT) (Weiner 1977, Parker and Robbins 1985). Energy may be more limited in roe deer than in red deer during winter because roe deer face severe constraints from its limited ability to digest typical winter forage like browse (Holand 1992, 1994). This is also evidenced from lower in vitro dry matter digestibility (IVDMD) of forage by roe deer than red deer in this area (Chen and Xiao 1991, Chen et al. 1998b). We predict that red deer and roe deer should show some differences in bed-site selection. We tested the following hypotheses: (1) roe deer should have higher canopy closure over beds than red deer; (2) day beds should be located under less dense canopy closure than night beds for both cervids; (3) canopy closure over beds should be correlated with temperature, thereby being highest during mid winter when temperature is lowest for both cervids.

\section{Study area}

The study was conducted at Tonghe Hunting Farm with an area of 30000 ha on the southern slope of the Less Xingan Mountains $\left(45^{\circ} 43^{\prime} \mathrm{N}, 128^{\circ} 40^{\prime} \mathrm{E}\right)$, northeastern China. Tonghe is a low mountain area. The topography is gentle, rising gradually from south to north. Elevation ranges from 400 to 900 $\mathrm{m}$. The climate is continental and characterized by long, cold winters, and short, hot summers. The annual average temperature is $2.4^{\circ} \mathrm{C}$, ranging from about $-40.4^{\circ} \mathrm{C}$ to $36.7^{\circ} \mathrm{C}$. The accumulated temperature above $10^{\circ} \mathrm{C}$ is $2200-2500^{\circ} \mathrm{C}$. The average annual precipitation is about $560-700 \mathrm{~mm}$. The frost-free period is 100-105 days, from late April to late September. Snow accumulates in late November, and persists until end of April, and the average snow depth is $43 \mathrm{~cm}$.

Typical vegetations are coniferous and broad-leaved mixed forest and oak Quercus mongolica forest. The investigation of the mixed forest conducted in winter of 1991, using the point-quarter sampling method (Goldsmith and Harrison 1976), showed that major trees were Fraxinus mandshurica (17.3\%, relative density), Pinus koraiensis $(15.1 \%)$, Tilia amurensis $(15.1 \%)$, Phellodendron amurense (8.5\%), Ulmus spp. (5.9\%), and Acer mono (3.7\%) (H. P. Chen, J. Z. Ma and F. Li, unpubl.). Understory shrubs mainly include Corylus mandshurica, Deutzia spp., Lonicera spp., Syringa amurensis, and Acanthopanax senticosus. Common herbaceous layer plants in forests are Carex spp., Urtica spp. and Aegopodium alpestre. 
Wild boar Sus scrofa is only one ungulate that is common in the study area besides red deer and roe deer. The other ungulates, such as musk deer Moschus moschiferus and common goral, Naemorhedus goral are rare. A survey, conducted in 1986 when the hunting farm was established, indicated that there were 79-175 red deer, $136-350$ roe deer, and 43-93 wild boars in the hunting farm (Z. X. Gao, unpubl.). It is believed that there is a little increase in ungulate populations after more than 10 years (personal communication). Carnivores in the study area include black bear Selenarctos thibetanus, brown bear Ursus arctus, yellow-throated marten Martes flavigula, sable Martes zibellina, and Leopard cat Felis bengalensis. However, the populations of these carnivores are generally very low.

\section{Material and methods}

\section{Tracking procedure}

Five sampling areas were chosen from the study area on the basis of vegetation and topography, each ranging from 50 to 200 ha in size. Beds were located by tracking cervids in snow from late November to late March 1991-1992. We selected randomly one area by using the random table and checked it each day. Each area was checked at least once during the sampling period of 7 to 10 days each month.

Cervids have a feeding-resting-feeding rhythm (Gates and Hudson 1983, Cederlund 1989). In a single day, red deer has 4-5 alternating bouts of foraging and resting (Gates and Hudson 1983) and roe deer usually has 5-11 separate feeding bouts (Danilkin and Hewison 1996). Leaving the night bedding site, cervids start an intensive feeding period shortly before first light. After active feeding, cervids moves to a day bedding site. To locate tracks three persons walked in parallel, each approximately 100 $\mathrm{m}$ apart. Night beds could be located by backtracking it while day beds by following it in the early morning when a fresh track was found. The fresh tracks were identified by an experienced hunter according to the looseness and puffiness of snow. Beds were marked and numbered, and measurements were taken later. Beds within a radius of $20 \mathrm{~m}$ of the first bed found were assumed to be within the same bedding site. Beds were distinguished between red deer and roe deer by the characteristics of tracks, size and scraping evidence of beds, and pellets. Within a bedding site one bed was chosen randomly as a representative, and habitat parameters were measured.

\section{Measurement of habitat factors}

At each bed site we counted total number of beds in a group, number of fresh beds in a group, measured size of beds, diameter at breast height of trees $(\mathrm{dbh}>7 \mathrm{~cm})$, distance to the nearest tree, height of trees, maximum canopy diameter of trees, distance to the nearest shrub $(\mathrm{dbh} \leq 7 \mathrm{~cm})$, height of shrubs, using the point-quarter sampling technique (Goldsmith and Harrison 1976), and recorded and estimated snow depth, distance to the point of human disturbance (local resident community, road, active logging areas etc.), slope aspect, slope gradient, slope position, percent canopy closure over beds, ground covers under $1 \mathrm{~m}$, and between 1 and $2.5 \mathrm{~m}$ above ground, percent conifer composition of the nearest trees in the 4 quadrants, and evidence of browsing and its percentage of browsed current annual growth of the nearest shrubs in the 4 quadrants. Canopy closure was measured following Kirchhoff and Schoen (1987). A black and white photograph of the canopy was taken at the center of each bed using an automatic $35-\mathrm{mm}$ camera and $80-\mathrm{mm}$ lens. The lens was projected vertically from a height of $0.5 \mathrm{~m}$ directly above ground. A 100 -dot grid was superimposed on each $9 \times 9$-cm photograph, and the number of points that overlapped canopy was recorded. Ground cover was measured using the cover density board of $0.3 \times 2.5 \mathrm{~m}$, which was marked off in $0.5 \mathrm{~m}$ intervals (Nudds 1977). The board was placed at the center of each bed and read from each of the four cardinal directions from a distance of $15 \mathrm{~m}$. The proportion of each $0.5 \mathrm{~m}$ interval obstructed by vegetation was recorded as a single-digit density score. Density scores 1 to 5 correspond to 0 to 20,21 to 40,41 to 60,61 to 80 , and 81 to $100 \%$. Measurements were taken as an average of scores from four directions. 


\section{Statistical analysis}

The data of 14 variables were subjected to principal component analysis (PCA) and discriminant function analysis (DFA) (the canonical discriminant analysis and stepwise discriminant analysis) (Cooley and Lohnes 1971). The measurements of relevant variables of the nearest tree in each of the 4 quadrants were taken as a mean that was used in the PCA and DFA. The PCA was used to identify the importance of habitat variables. The DFA was used to select those variables that best discriminated between day and night beds of two cervids (Armstrong et al. 1983a, b). The Fisher's protected least significant difference (FPLSD) was used to compare the difference in each habitat variable among day and night beds of two cervids. $\chi^{2}$-test was used to test if night beds occurred more on north-facing slopes while day beds on south-facing slopes, and if there was less browsing at night beds than day beds. The computation was carried out in SAS procedures (SAS 1989).

\section{Results}

All roe deer $(n=128)$ beds were scraped whereas red deer $(n=75)$ never scraped beds. There was no significant difference in number of fresh beds and total number of beds between red deer and roe deer, and between day and night bedding sites for both cervids. Night beds were larger than day beds for roe deer. However, no significant difference was found in depth of beds. Night beds were longer than day beds for red deer whereas no significant difference existed in width and depth of beds (Table 1 ).

Night beds were associated with higher canopy closure than day beds for both cervids $(p<0.05)$. Red deer bedded closer to trees during night than during day whereas no such difference was found in roe deer. Night beds were surrounded more by coniferous trees and were less concealed than day beds for roe deer $(p<$ $0.05)$ whereas no such differences were found for red deer $(p>0.05)$. Bedding sites were deeper in snow for red deer than roe deer $(p<0.05)$ (Table 2). For both cervids most night beds were located on north-facing slopes $(61.6 \%$ and $62.5 \%$ for red deer and roe deer, respectively) whereas most day bed sites were on south-facing slopes (60.8\% and $57.5 \%$ for red deer and roe deer, respectively) $\left(p<0.05, \chi^{2}=8.25\right.$ for red deer and $\chi^{2}=6.56$ for roe deer, respectively). No significant differences were found

Table 1. Characteristics (mean $\pm \mathrm{SE}$ ) of red deer and roe deer beds during winter in the forests of northeastern China (1991-1992). The different letters at the same row indicated a significant difference at $p<0.05$ (the Fisher's protected least significant difference). $n$-sample size.

\begin{tabular}{|c|c|c|c|c|c|c|c|c|}
\hline & \multicolumn{4}{|c|}{ Red deer } & \multicolumn{4}{|c|}{ Roe deer } \\
\hline & Day & $n$ & Night & $n$ & Day & $n$ & Night & $n$ \\
\hline Number of fresh beds & $1.7 \pm 0.4^{\mathrm{a}}$ & 23 & $1.5 \pm 0.3^{\mathrm{a}}$ & 26 & $1.4 \pm 0.2^{\mathrm{a}}$ & 36 & $1.7 \pm 0.4^{\mathrm{a}}$ & 36 \\
\hline Total number of beds & $1.7 \pm 0.4^{\mathrm{a}}$ & 23 & $1.6 \pm 0.3^{\mathrm{a}}$ & 26 & $1.8 \pm 0.4^{\mathrm{a}}$ & 36 & $1.8 \pm 0.4^{\mathrm{a}}$ & 36 \\
\hline Length of beds $(\mathrm{cm})$ & $123.9 \pm 4.9^{\mathrm{b}}$ & 34 & $132.8 \pm 8.3^{\mathrm{a}}$ & 41 & $78.1 \pm 2.6^{\mathrm{c}}$ & 63 & $83.6 \pm 3.2^{\mathrm{d}}$ & 65 \\
\hline Width of beds (cm) & $78.7 \pm 4.2^{\mathrm{a}}$ & 34 & $79.7 \pm 4.7^{\mathrm{a}}$ & 41 & $52.6 \pm 2.9^{\mathrm{b}}$ & 63 & $58.1 \pm 3.1^{\mathrm{c}}$ & 65 \\
\hline Depth of beds (cm) & $19.3 \pm 2.4^{\mathrm{a}}$ & 34 & $20.2 \pm 2.6^{\mathrm{a}}$ & 41 & $15.6 \pm 1.9^{b}$ & 63 & $16.1 \pm 2.1^{\mathrm{b}}$ & 65 \\
\hline
\end{tabular}


Table 2. Characteristics (mean $\pm \mathrm{SE}$ ) of bedding sites of red deer and roe deer during winter in the forests of northeastern China (1991-1992). SND - snow depth (cm), HDD - distance to the points of human disturbance (m), SG - slope, SP - slope position, CC - canopy closure (\%), GC1 - ground cover $(<1 \mathrm{~m}), \mathrm{GC} 2$ - ground cover $(>1 \mathrm{~m}), \mathrm{CP}$ - coniferous composition $(\%)$, TD - average distance to the nearest tree within each of the 4 quadrants $(\mathrm{m})$, TBD - average diameter at breast height of the nearest tree within each of the 4 quadrants $(\mathrm{cm})$, TH - average height of the nearest tree within each of the 4 quadrants (m), TCD - average maximum canopy diameter of the nearest tree within each of the 4 quadrants $(\mathrm{m}), \mathrm{SBD}$ - average distance to the nearest shrub within each of the 4 quadrants $(\mathrm{m})$, SBH - average height of the nearest shrub within each of the 4 quadrants $(\mathrm{m})$. Different letters at the same row indicated a significant difference at $p<0.05$ (the Fisher's protected least significant difference).

\begin{tabular}{lcrrrr}
\hline & \multicolumn{2}{c}{ Red deer } & \multicolumn{2}{c}{ Roe deer } \\
\cline { 2 - 3 } \cline { 5 - 6 } & Day $(n=22)$ & Night $(n=26)$ & & Day $(n=41)$ & Night $(n=38)$ \\
\hline SND & $21.0 \pm 3.9^{\mathrm{a}}$ & $20.5 \pm 3.2^{\mathrm{a}}$ & & $15.6 \pm 2.5^{\mathrm{b}}$ & $13.5 \pm 2.6^{\mathrm{b}}$ \\
HDD & $818.2 \pm 110.8^{\mathrm{a}}$ & $865.4 \pm 92.7^{\mathrm{a}}$ & & $890.2 \pm 67.0^{\mathrm{a}}$ & $881.6 \pm 71.1^{\mathrm{a}}$ \\
SG & $18.5 \pm 4.2^{\mathrm{a}}$ & $15.8 \pm 5.0^{\mathrm{a}}$ & & $16.2 \pm 3.7^{\mathrm{a}}$ & $14.1 \pm 2.4^{\mathrm{a}}$ \\
SP & $2.2 \pm 0.5^{\mathrm{a}}$ & $1.9 \pm 0.3^{\mathrm{a}}$ & & $2.1 \pm 0.3^{\mathrm{a}}$ & $1.9 \pm 0.3^{\mathrm{a}}$ \\
CC & $23.5 \pm 12.2^{\mathrm{a}}$ & $49.6 \pm 12.0^{\mathrm{b}}$ & & $21.6 \pm 6.5^{\mathrm{a}}$ & $78.5 \pm 7.4^{\mathrm{c}}$ \\
GC1 & $1.9 \pm 0.5^{\mathrm{a}}$ & $2.0 \pm 0.3^{\mathrm{a}}$ & & $2.9 \pm 0.4^{\mathrm{b}}$ & $2.1 \pm 0.3^{\mathrm{a}}$ \\
GC2 & $1.9 \pm 0.5^{\mathrm{a}}$ & $2.1 \pm 0.3^{\mathrm{a}}$ & & $3.1 \pm 0.4^{\mathrm{b}}$ & $2.3 \pm 0.3^{\mathrm{a}}$ \\
CP & $9.1 \pm 5.5^{\mathrm{a}}$ & $15.4 \pm 11.6^{\mathrm{a}}$ & & $4.3 \pm 3.5^{\mathrm{a}}$ & $32.2 \pm 10.5^{\mathrm{b}}$ \\
TD & $7.1 \pm 2.3^{\mathrm{a}}$ & $4.0 \pm 0.9^{\mathrm{b}}$ & & $3.7 \pm 0.5^{\mathrm{b}}$ & $3.1 \pm 0.3^{\mathrm{b}}$ \\
TBD & $16.0 \pm 2.5^{\mathrm{a}}$ & $18.4 \pm 2.1^{\mathrm{a}}$ & & $17.0 \pm 1.3^{\mathrm{a}}$ & $17.5 \pm 1.4^{\mathrm{a}}$ \\
TH & $12.1 \pm 1.0^{\mathrm{a}}$ & $12.2 \pm 0.9^{\mathrm{a}}$ & & $13.2 \pm 0.9^{\mathrm{a}}$ & $12.1 \pm 0.7^{\mathrm{a}}$ \\
TCD & $3.4 \pm 0.5^{\mathrm{a}}$ & $4.0 \pm 0.5^{\mathrm{a}}$ & & $3.8 \pm 0.5^{\mathrm{ab}}$ & $4.3 \pm 0.5^{\mathrm{b}}$ \\
SBD & $1.8 \pm 0.9^{\mathrm{a}}$ & $1.1 \pm 0.2^{\mathrm{b}}$ & & $1.0 \pm 0.5^{\mathrm{b}}$ & $1.0 \pm 0.1^{\mathrm{b}}$ \\
SBH & $1.2 \pm 0.5^{\mathrm{a}}$ & $1.2 \pm 0.4^{\mathrm{a}}$ & & $1.3 \pm 0.3^{\mathrm{a}}$ & $1.3 \pm 0.2^{\mathrm{a}}$ \\
\hline
\end{tabular}

in canopy closure between mid and late winter for night and day beds of red deer (Fig. 1). However, roe deer had higher canopy closure over night beds during mid winter (low temperature) than early and late winter (relatively high temperature) $(p<0.05)$ whereas such difference was not observed for day beds $(p>0.05)$ (Fig. 2).

There was less browsing at night beds $(7.7 \%, n=26)$ than day beds $(31.8 \%, n=$ 22 ) for red deer $\left(p<0.05, \chi^{2}=4.64\right)$ whereas no such difference was observed for roe deer $\left(p>0.05, \chi^{2}=0.83,18.4 \%\right.$ at night beds, $n=38 ; 26.8 \%$ at day beds, $n=$ 41). No difference was found in the average percentage of browsed twigs between day and night beds for both cervids, and between red deer and roe deer bedding sites $(p>0.05$, FPLSD).

The first principal component accounted for $20.5 \%$ of the variance, and represented the changes in average maximum canopy diameter of the nearest tree within each of the 4 quadrants (TCD), canopy closure (CC), slope (SG), and slope position 


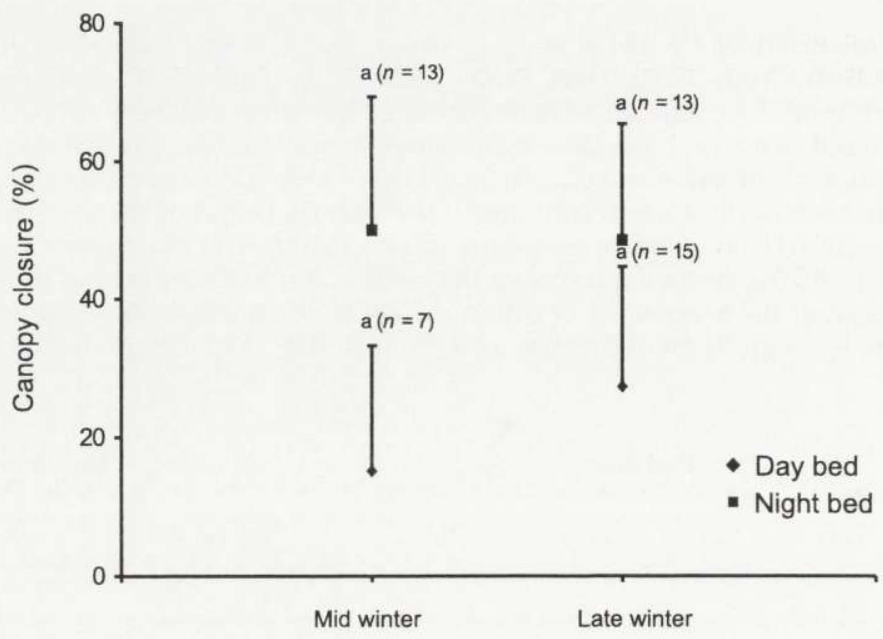

Fig. 1. The canopy closure (mean with one standard error bar) of red deer beds throughout the winter. The same legend key with the different letters indicated a significant difference at $p<0.05$ (Fisher's protected least significant difference).

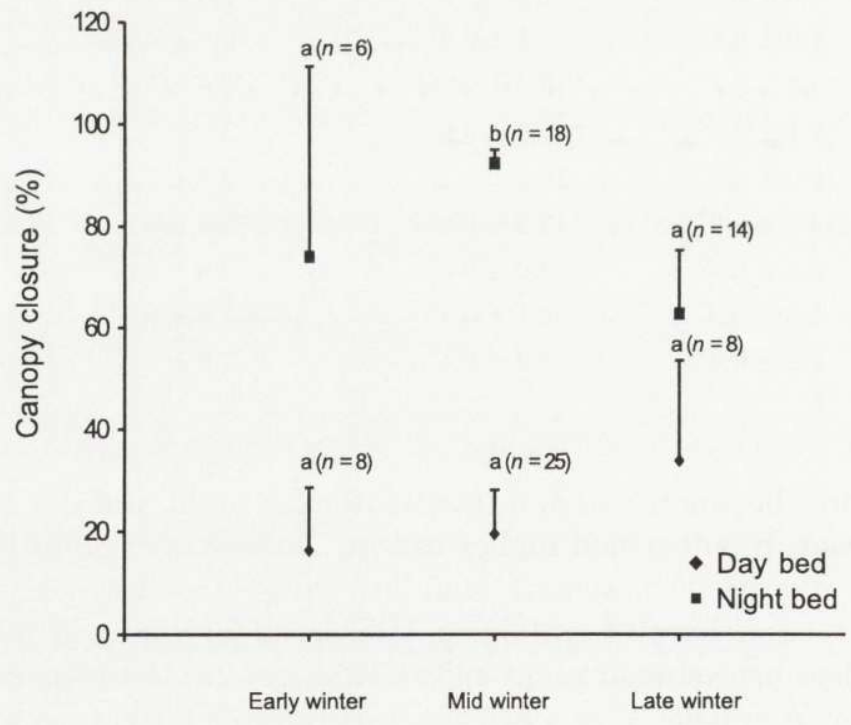

Fig. 2. The canopy closure (mean with one standard error bar) of roe deer beds throughout the winter. The same legend key with the different letters indicated a significant difference at $p<0.05$ (Fisher's protected least significant difference).

(SP) (Table 3). The second principal component was positively correlated with ground cover (GC1 and GC2) and average diameter at breast height of the nearest tree within each of the 4 quadrants (TBD), and negatively correlated with average 
Table 3. Principal component analysis (PCA) of bedding sites of red deer and roe deer during winter in the forests of northeastern China (1991-1992). ${ }^{a}$ See Table 2 for abbreviations, ${ }^{b}$ Cumulative proportion of variance explained $(\%),{ }^{c}$ Values less than 0.30 have been replaced by 0.0 .

\begin{tabular}{|c|c|c|c|c|c|c|}
\hline \multirow{2}{*}{ Variable } & \multicolumn{6}{|c|}{ Eigenvectors } \\
\hline & $\mathrm{I}(20.5)^{\mathrm{b}}$ & II (35.8) & III (48.4) & IV (60.6) & $\mathrm{V}(68.6)$ & VI (75.3) \\
\hline $\mathrm{SND}^{\mathrm{a}}$ & $0.0^{\mathrm{c}}$ & 0.0 & 0.0 & -0.335 & 0.376 & 0.321 \\
\hline HDD & 0.0 & 0.0 & 0.0 & 0.366 & 0.0 & 0.0 \\
\hline SG & 0.348 & 0.0 & 0.0 & 0.0 & 0.0 & 0.0 \\
\hline SP & 0.333 & 0.0 & 0.0 & 0.389 & 0.0 & -0.328 \\
\hline $\mathrm{CC}$ & -0.339 & 0.0 & 0.0 & 0.372 & 0.349 & 0.0 \\
\hline GC1 & 0.0 & 0.430 & 0.0 & 0.0 & 0.0 & 0.308 \\
\hline $\mathrm{GC} 2$ & 0.0 & 0.445 & -0.370 & 0.0 & 0.0 & 0.0 \\
\hline $\mathrm{CP}$ & 0.0 & 0.0 & 0.0 & 0.430 & 0.0 & 0.431 \\
\hline TD & 0.0 & 0.0 & 0.495 & 0.0 & 0.0 & 0.385 \\
\hline TBD & -0.309 & 0.370 & 0.331 & 0.0 & 0.0 & 0.0 \\
\hline $\mathrm{TH}$ & 0.0 & 0.0 & 0.379 & 0.0 & 0.0 & 0.0 \\
\hline TCD & -0.400 & 0.0 & 0.0 & 0.0 & 0.0 & 0.0 \\
\hline SBD & 0.0 & -0.354 & 0.0 & 0.0 & 0.0 & 0.493 \\
\hline SBH & 0.0 & 0.0 & 0.0 & 0.0 & 0.687 & 0.0 \\
\hline
\end{tabular}

distance to the nearest shrub within each of the 4 quadrants (SBD). The fourth principal component was positively correlated with coniferous composition (CP), SP, CC, distance to the points of human disturbance (HDD), and negatively correlated with snow depth (SND). The fifth principal component was highly correlated with average height of the nearest shrub within each of the 4 quadrants (SBH), and the sixth principal component was highly correlated with SBD and CP. The first six principal components accounted for $75.3 \%$ of variance in the bed data set.

The stepwise discriminant analysis indicated that five variables were selected to discriminate between day and night bed sites for both cervids. These variables were CC $\left(R^{2}=0.514, p<0.0001\right)$, average distance to the nearest tree within each of the 4 quadrants (TD) $\left(R^{2}=0.193, p<0.0001\right)$, GC2 $\left(R^{2}=0.156, p<0.0001\right)$, average height of the nearest tree within each of the 4 quadrants (TH) $\left(R^{2}=0.095, p<\right.$ $0.0073)$, and SND $\left(R^{2}=0.0932, p<0.0085\right)$. The canonical discriminant analysis indicated that red deer and roe deer had different selection in bedding sites (Fig. 3). Moreover, roe deer showed much more difference between day and night beds than red deer. The first canonical variable was strongly negatively correlated with $\mathrm{CC}$ and $\mathrm{CP}$. The second canonical variable was negatively correlated with TD and GC2. 


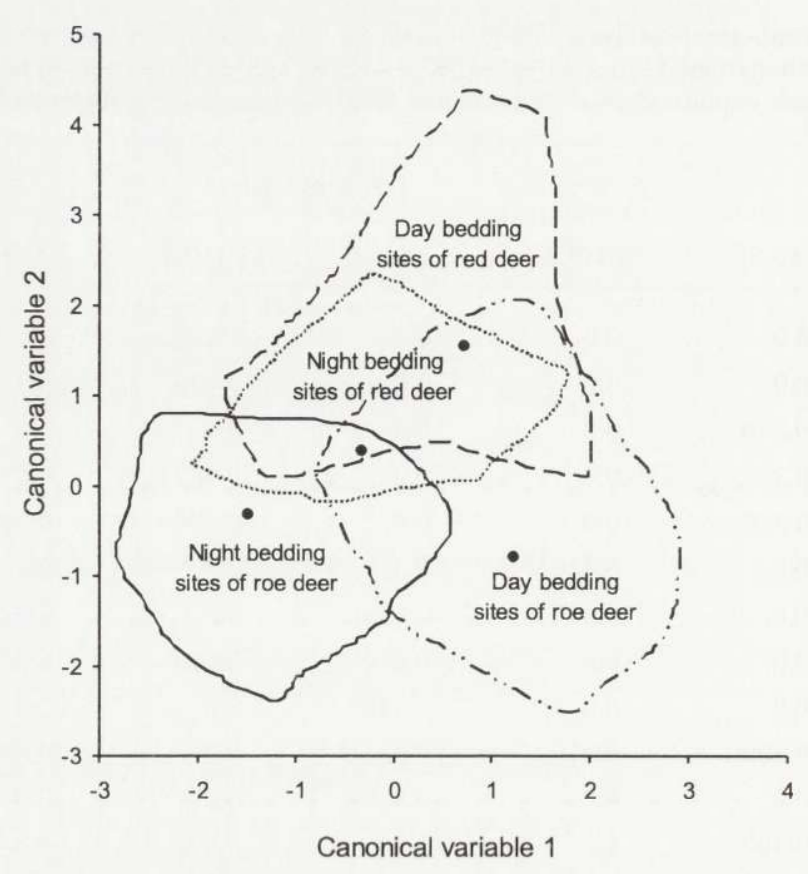

Fig. 3. Two-dimensional discriminant ordination of day and night beds of red deer and roe deer in the forests of northeastern China (1991-1992). Solid circles represented the mean; lines delimit range of values.

\section{Discussion}

In practice, it is very difficult to determine and identify whether tracks are fresh and judge whether beds are used during day and night. To reduce and avoid such bias from our observation in this study, we started tracking work in the early morning and asked a hunter with over 30 years hunting experience to handle these thorny problems. However, some conclusions would be cautious due to some confusion in the identification of tracks.

Scraping the beds has been described as a comfort behavior and possibly also as an energy-conserving strategy (Sergeant et al. 1994, Mysterud and Østbye 1995, Mysterud 1996). This behaviour seems to be unique to roe deer and was seldom reported in other deer species, except for mule deer Odocoileus hemionus in arid environment (Sergeant et al. 1994). Mysterud and Østbye (1995) indicated that half of roe deer beds were scraped. In this study roe deer scraped all day and night beds whereas red deer never scraped any beds. This difference in the characteristics of beds between red deer and roe deer was also noticed by Chang and Xiao (1988).

Vegetation structure affects microclimates. Thermal cover is mainly composed of the timber stands with overstory (Huot 1974). Height, canopy closure, and stem 
density modify temperature, wind speed, precipitation, and radiation within stands. Thus, thermal cover is important for cervids to maintain an energy balance between fixed body-temperature demand and extremes in ambient temperature (Skovlin 1982). Strong preference to bedding below coniferous species during winter was widely reported in several deer species (Beall 1974, Huot 1974, Armstrong et al. 1983b, Lang and Gates 1985, Smith et al. 1986, Mysterud and Østbye 1995). The same pattern in bed-site selection was observed in this study, which was further supported by the results from PCA and DFA of bed data sets (Table 3 and Fig. 3). Moreover, as predicted by our first hypothesis, roe deer selected a bed site with a higher canopy closure than red deer during night (Table 2). Armstrong et al. (1983b) indicated that the canopy closure and conifer composition of white-tailed deer Odocoileus virginianus day beds were significantly lower than those of night beds. Similar results were obtained in roe deer but red deer showed no significant difference in the conifer composition between day and night beds (Table 2). These results were generally consistent with our second hypothesis.

Small-bodied deer like roe deer and white-tailed deer seemed to seek higher percentage canopy closure during cold period than mild period (Huot 1974, Mysterud and Østbye 1995). However, in this study the larger red deer showed no significant difference in selection of canopy closure between the cold mid and warm late winter periods (Fig. 1).

In the great Xingan Mountain region of China, Jiang et al. (1996) reported that the diameter at breast height $(\mathrm{DBH})$ of trees and canopy coverage of shrubs (defined as the trees between 0.5 and $3 \mathrm{~m}$ in height) were lower in the bedding sites of roe deer than the randomly sampled sites, and there was no significant difference in the canopy coverage of trees (defined as those with the heights of over $3 \mathrm{~m}$ ) between the bedding sites and the randomly sampled sites. These results were contrary to those reported by Mysterud and Østbye (1995). Schmitz (1991) indicated that white-tailed deer selected the open habitats to avoid overheating during daylight, and the study by Jiang et al. (1996) was indeed conducted during the warmer period from October 20 to December 20.

Elk seemed to prefer to bed near a large tree (Beall 1974) whereas roe deer did not bed as close to the trunk as possible (Mysterud and Østbye 1995). In this study, day beds of red deer were farther from the trunk than night beds, and roe deer beds of both types. No significant difference existed in the distance of night beds to the nearest tree between red deer and roe deer (Fig. 4). Armstrong et al. (1983b) reported that night beds were closer to trees than day beds, which is opposite to our results for roe deer.

Day beds were usually on the south-facing slopes and night beds on the north-facing slopes (Beall 1974, Armstrong et al. 1983b). This pattern was found in this study and it could be explained by the fact that north-facing slopes usually furnish the heaviest forest cover types because of their relatively moist conditions (Skovlin 1982).

Most beds were high up on slopes in several deer species (Beall 1974, Armstrong et al. 1983b, Mysterud and Østbye 1995, Jiang et al. 1996). This is explained as an 


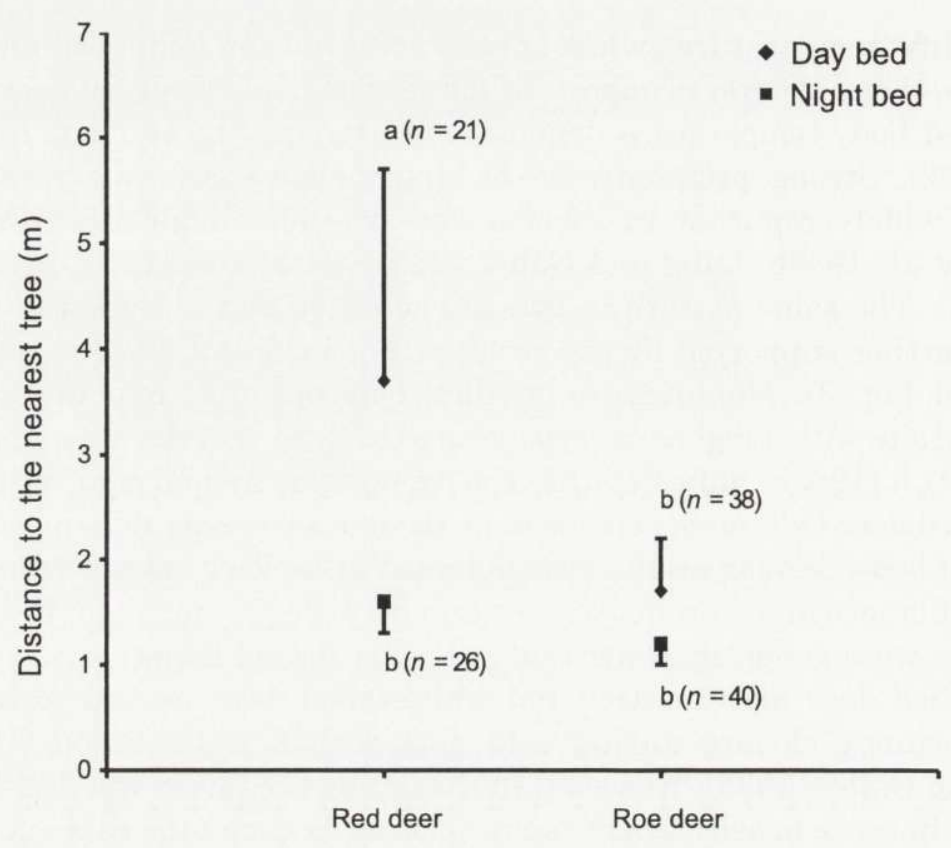

Fig. 4. The distance (mean with one standard error bar) of red deer and roe deer beds to the nearest tree. The legend keys with the different letters indicated a significant difference at $p<0.05$ (Fisher's protected least significant difference).

antipredator strategy (Mysterud and Østbye 1995) or more easily obtaining solar energy (Jiang et al. 1996). Similar results were observed in this study (Table 2).

Hiding cover is the other important component of bedding habitats and provides cervids security or a means of escape from the threat of predators or harassment. Dense ground cover was usually used by cervid calves to escape predators (Barret 1981, Gerlach and Vaughan 1991). Roe deer beds had good ground cover during winter in Norway (Mysterud and Østbye 1995). The same result was observed in day beds of roe deer in this study (Table 2). Day beds of roe deer had better concealment cover than night beds (Table 2). This phenomenon was also observed in other studies in which roe deer and moose used open habitat more often at night (Hjeljord et al. 1990, Histøl 1992). In this study area the human hunting is main predation pressure against roe deer. Selecting dense ground cover of day beds might be looked as an antipredator strategy in roe deer. Red deer was easily conditioned to repeated patterns of human activity (Skovlin 1982) and thus might be inert to human disturbances. This may explain the difference in the concealment of day and night beds between red deer and roe deer.

Zhang and Xiao (1990) indicated that the horizontal cover density, distance from human disturbance, and wind direction were main factors in determining selection of bedding sites for red deer. However, the later two factors could not be identified as determinant factors in bed-site selection of red deer using PCA and DFA 
techniques in this study. PCA and DFA indicated that CC, TD, GC2, and TH were main determinants in bed-site selection of red deer and roe deer.

In conclusion, red deer and roe deer showed some significant differences in bed-site selection (Fig. 3). Roe deer selected night bedding sites with denser canopy closure and higher percentage of coniferous trees, and day beds with better concealment cover than red deer. These differences reflected the changes in thermal and hiding covers, which may be closely related and linked to energy requirements of both cervids.

Acknowledgements: We thank numerous personnel from the Tonghe Hunting Farm for the field assistance. Special thanks to Du Yongxin and Li Jie, managers of farm, who graciously contributed their time and effort in completing this study. We are very grateful to Dr Atle Mysterud and an anonymous reviewer for their helpful comments and English improvement on the early draft of this manuscript. Also, special thanks is extended to Dr Mysterud who kindly sent me reprints of his published papers and a copy of his Ph D thesis. This study was supported by the National Nature Science Foundation of China (No. 39070160).

\section{References}

Armstrong E., Euler D. and Racey G. 1983a. White-tailed deer habitat and cottage development in central Ontario. The Journal of Wildlife Management 47: 605-612

Armstrong E., Euler D. and Racey G. 1983b. Winter bed-site selection by white-tailed deer in central Ontario. The Journal of Wildlife Management 47: 880-884.

Barrett M. W. 1981. Environmental characteristics and functional significance of pronghorn fawn bedding sites in Alberta. The Journal of Wildlife Management 45: 120-131.

Beall R. C. 1974. Winter habitat selection and use by a western Montana elk herd. Ph D thesis, University of Montana, Missoula: 1-176.

Cederlund G. 1989. Activity patterns in moose and roe deer in a north boreal forest. Holarctic Ecology 12: $39-45$

Chang H. and Xiao Q. Z. 1988. Selection of winter habitat of red deer in Dailing region. Acta Theriologica Sinica 8: 81-88. [In Chinese with English summary]

Chen H. P. and Xiao Q. Z. 1989. Winter food-habits of red deer in Dailing. Acta Theriologica Sinica 9: 8-15. [In Chinese with English summary]

Chen H. P. and Xiao Q. Z. 1991. Comparison of winter trophic strategies between red deer and roe deer in Dailing region. Acta Ecologica Sinica 11: 349-354 [In Chinese with English summary]

Chen H. P., Ma J. Z., Li F., Sun Z. W., Wang H., Luo L. Y. and Li F. 1998a. Seasonal composition and quality of wapiti Cervus elaphus diets in northeastern China. Acta Theriologica 43: 77-94.

Chen H. P., Ma J. Z., Sun Z. W., Li F., Wang H., Luo L. Y. and Li F. 1998b. In vitro digestibility of seasonal forages used by wapiti and roe deer in northeastern China. Ecography 21: 11-17.

Cooley W. W. and Lohnes P. R. 1971. Multivariate data analysis. J. Wiley \& Sons, New York, N. Y.: 1-364.

Danilkin A. and Hewison A. J. M. 1996. Behavioural ecology of Siberian and European roe deer. Chapman and Hall, London: 1-270.

Gates C. C. and Hudson R. J. 1983. Foraging behaviour of wapiti in a boreal forest enclosure. Naturaliste Canadien 110: 197-206.

Gerlach T. P. and Vaughan M. R. 1991. Mule deer fawn bed site selection on the Pinon canyon maneuver site, Colorado. Southwest Naturalist 36: 255-258.

Goldsmith F. B. and Harrison C. M. 1976. Description and analysis of vegetation. [In: Methods in plant ecology. S. B. Chapman, ed]. Blackwell Scientific Publications, Oxford: 85-155.

Histøl T. 1992. Winter feeding strategy of migrating and non-migrating moose, Alces alces (L.), in Østfold, Norway. M Sc thesis, University of Oslo, Oslo: 1-65. 
Hjeljord O., Hovik N. and Pedersen H. B. 1990. Choice of feeding sites by moose during summer, the influence of forest structure and plant phenology. Holarctic Ecology 13: 281-292.

Holand Ø. 1992. Winter digestive strategy of a concentrate selector in Norway: the European roe deer. Canadian Journal of Zoology 70: 1331-1335.

Holand Ø. 1994. Seasonal dynamics of digestion in relation to diet quality and intake in European roe deer (Capreolus capreolus). Oecologia 98: 274-279.

Huot J. 1974. Winter habitat of white-tailed deer at Thirty-one Mile Lake, Quebec. The Canadian Field-Naturalist 88: 293-301.

Jiang Z. W., Xu L., Wang Y. Q., Jiao P. R. and Liu H. F. 1996. Winter resting site selection by roe deer at Huzhong, Daxinganling Mountains, northeastern China. Zoological Research 17: 108, $128,138$.

Kirchhoff M. D. and Schoen J. W. 1987. Forest cover and snow: implications for deer habitat in southeast Alaska. The Journal of Wildlife Management 51: 28-33.

Lang B. K. and Gates J. E. 1985. Selection of sites for winter night beds by white-tailed deer in a hemlock-northern hardwood forest. The American Naturalist 113: 245-254.

Ma J. Z., Chen H. P., Sun Z. W., Li F., Wang H., Li F., Du Y. X. and Li J. 1996. Seasonal nutritional quality of red deer and roe deer forages in southern Xiao Xingan Mountains, China. Acta Ecologica Sinica 16: 269-275. [In Chinese with English summary]

Mautz W. W. 1978. Sledding on a bushy hillside: the fat cycle in deer. Wildlife Society Bulletin 6: 88-90.

Moen A. N. 1976. Energy conservation by white-tailed deer in the winter. Ecology 57: 192-198.

Moen A. N. 1985. Energy metabolism of deer in relation to environmental variables. Biology of deer production, Royal Society of New Zealand Bulletin 22: 439-445.

Mysterud A. 1996. Bed-site selection by adult roe deer Capreolus capreolus in southern Norway during summer. Wildlife Biology 2: 101-106.

Mysterud A. and Østbye E. 1995. Bed-site selection by European roe deer (Capreolus capreolus) in southern Norway during winter. Canadian Journal of Zoology 73: 924-932.

Nudds T. D. 1977. Quantifying the vegetation structure of wildlife cover. Wildlife Society Bulletin 5: $113-117$.

Parker K. L. and Robbins C. T. 1984. Thermoregulation in mule deer and elk. Canadian Journal of Zoology 62: 1409-1422.

Parker K. L. and Robbins C. T. 1985. Thermoregulation in ungulates. [In: Bioenergetics of wild herbivores. R. J. Hudson and R. G. White, eds]. CRC Press, Inc., Boca Raton, Florida: 161-182.

Risenhoover K. L. 1986. Winter activity patterns of moose in interior Alaska. The Journal of Wildlife Management 50: 727-734.

Sergeant G. A., Eberhardt L. E., and Peek J. M. 1994. Thermoregulation by mule deer (Odocoileus hemionus) in arid rangelands of southcentral Washington. Journal of Mammalogy 75: 536-544.

SAS. 1989. SAS user's guide: statistics. SAS Institute Inc., Cary, N. C.: 1-890.

Schmitz O. J. 1991. Thermal constraints and optimization of winter feeding and habitat choice in white-tailed deer. Holarctic Ecology 14: 104-111.

Skovlin J. M. 1982. Habitat requirements and evaluations. [In: Elk of North America: ecology and management. J. W. Thomas and D. E. Toweill, eds]. Stackpole Books, Harrisburg, Pennsylvania: 369-413.

Smith H. D., Oveson M. C. and Pritchett C. L. 1986. Characteristics of mule deer beds. Great Basin Naturalist 46: 542-546.

Verme L. J. and Ullrey D. E. 1984. Physiology and nutrition. [In: White-tailed deer ecology and management. L. K. Halls, ed]. Stackpole Books, Harrisburg, Pennsylvania: 91-118.

Weiner J. 1977. Energy metabolism of the roe deer. Acta Theriologica 22: 3-24.

Zhang M. H. and Xiao Q. Z. 1990. A study on feeding and bedding habitat selection by red deer in winter. Acta Theriologica Sinica 10: 175-183. [In Chinese with English summary]

Received 29 November 1997, accepted 30 November 1998. 